\title{
Strategi Komunikasi Pemasaran Adroady Media dalam Memperkenalkan Car Videotron Sebagai Media Iklan Luar Ruang Baru
}

\author{
Angellisa Salim, Gregorius Genep Sukendro \\ angellisasalim@gmail,com,geneps@fikom.untar.ac.id \\ Fakultas Ilmu Komunikasi Universitas Tarumanagara
}

\begin{abstract}
This study discusses Adroady Media's marketing communication strategy in introducing Car Videotron as a new outdoor advertising media. The purpose of this research is to find out how the marketing communication strategy used by Adroady Media companies in promoting new outdoor advertising media is Car Videotron to be known by consumers and potential customers. This type of research used by researchers is to use descriptive qualitative methods. Data collection techniques are done through observation, in-depth interviews and through literature and internet studies. Researchers use several theories to support this research, namely advertising, marketing communication strategies, outdoor media, new media. The results of this study indicate that the marketing communication strategy adopted by Adroady Media is to use 3 types of communication media, namely personal selling, direct marketing, and events or experiences. From these three media, it can be concluded that personal selling is the most effective media used in Car Videotron marketing. With personal selling, the company Adroady Media can establish good relationships with consumers and potential customers and build good relationships.
\end{abstract}

Keywords: adroady media, car videotron, marketing communication strategy, new media

\begin{abstract}
Abstrak
Penelitian ini membahas tentang strategi komunikasi pemasaran Adroady Media dalam memperkenalkan Car Videotron sebagai media iklan luar ruang baru. Tujuan dari penelitian ini untuk mengetahui bagaimana strategi komunikasi pemasaran yang dilakukan perusahaan Adroady Media dalam mempromosikan media iklan luar ruang baru yaitu Car Videotron agar dikenal oleh para konsumen, dan calon konsumen. Jenis penelitian yang digunakan peneliti yaitu menggunakan metode kualitatif deskriptif. Teknik pengumpulan data dilakukan melalui observasi, wawancara mendalam serta melalui studi kepustakaan dan internet. Peneliti menggunakan beberapa teori untuk mendukung penelitian ini yaitu periklanan, strategi komunikasi pemasaran, media luar ruang, new media. Dari hasil dari penelitian ini menunjukkan bahwa strategi komunikasi pemasaran yang dilakukan Adroady Media yaitu menggunakan 3 macam media komunikasi yaitu personal selling, pemasaran langsung, dan acara atau pengalaman. Dari ketiga media tersebut, dapat disimpulkan bahwa personal selling merupakan media yang paling efektif digunakan dalam pemasaran Car Videotron. Dengan personal selling, perusahaan Adroady Media bisa menjalin hubungan yang baik dengan konsumen maupun calon konsumen dan membangun relasi yang baik.
\end{abstract}

Kata Kunci: adroady media, car videotron, media baru, strategi komunikasi pemasaran 


\section{Pendahuluan}

Sampai saat ini industri periklanan masih menjadi sebuah media yang dapat mempengaruhi kehidupan masyarakat. Masyarakat itu sendiri merupakan sekelompok konsumen yang menjadi target pasar suatu perusahaan untuk membeli produknya. Salah satu perusahaan yang akan peneliti bahas yaitu Adroady Media. Adroady media merupakan perusahaan startup periklanan yang menghadirkan cara beriklan digital mobile out of home yang sifatnya berbeda dengan media iklan lainnya. Media iklan yang ditawarkan yaitu menggunakan mobil sebagai media pendukungnya, berbasis digital, dan mengandalkan jaringan DOOH LED pertama di dunia. Media iklan ini disebut dengan car advertising atau car videotron.

Memunculkan media iklan car videotron yang berbeda dengan media iklan luar ruang lainnya seperti billboard, spanduk, banner. Tentu hal ini juga, menjadi tantangan bagi Adroady media sebagai perusahaan yang baru terjun didunia periklanan dalam melakukan strategi komunikasi pemasaran untuk memperkenalkan sekaligus menarik konsumen.

Untuk itu, rumusan masalah dan tujuan dalam penelitian ini adalah untuk mengetahui bagaimana strategi komunikasi pemasaran Adroady Media dalam memperkenalkan Car Videotron sebagai media iklan luar ruang baru. Strategi komunikasi pemasaran itu sendiri merupakan suatu perencanaan yang dibuat oleh perusahaan untuk mencapai hasil dan tujuan sesuai keinginan perusahaan. Agar tujuan tersebut tercapai, sebuah perusahaan harus memiliki langkah yang efektif agar komunikasi pemasaran dapat terkomunikasikan dan dipromosikan dengan baik yaitu mengidentifikasi khalayak yang dituju, merancang pesan, menentukan tujuan komunikasi, memilih saluran komunikasi, menentukan total anggaran pemasaran/promosi, menentukan keputusan atas bauran komunikasi pemasaran, mengukur hasil promosi, mengelola dan mengkoordinasikan proses komunikasi pemasaran terintegrasi.

Selain itu, di dalam langkah tersebut juga terdapat saluran komunikasi pemasaran yang digunakan Adroady media dalam menarik para konsumennya yaitu dengan menggunakan media sosial seperti Instagram. Lalu komunikasi pemasaran lain yang dilakukan oleh Adroady media yaitu dengan melalui penjualan personal, pemasaran langsung dan event atau pengalaman. Ketiga komunikasi pemasaran, inilah yang akan diteliti di dalam penelitian ini.

\section{Metode Penelitian}

Dalam penelitian ini, penulis menggunakan pendekatan penelitian kualitatif dengan analisis deskriptif. Penelitian ini dilakukan oleh penulis untuk mengetahui bagaimana strategi komunikasi pemasaran Adroady Media dalam memperkenalkan car videotron sebagai media iklan luar ruang baru. Menurut Sugiyono (2016) pendekatan kualitatif digunakan untuk mendapatkan data yang mendalam, suatu data yang mengandung makna. Makna adalah data yang sebenarnya, data yang pasti merupakan nilai di balik data yang tampak. Oleh karena itu dalam penelitian kualitatif tidak menekankan pada generalisasi, tetapi lebih menekankan pada makna.

Metode penelitian yang digunakan oleh peneliti dalam penelitian ini adalah dengan menggunakan metode studi kasus. Menurut Kriyantono (2010), studi kasus adalah metode riset yang menggunakan berbagai sumber data (sebanyak mungkin data) yang bisa digunakan untuk meneliti, mengurai, dan menjelaskan secara 
komprehensif berbagai aspek individu, kelompok, suatu program, organisasi atau peristiwa secara sistematis.

Peneliti menggunakan studi kasus sebagai metode penelitian ini untuk mengetahui, mencari dan mengumpulkan informasi-informasi yang lebih mendalam terkait pada kasus dan masalah dalam penelitian ini. Didalam proses pengumpulan data informasi, peneliti menggunakan metode observasi, wawancara, dokumentasi dan studi kepustakaan.

Seperti yang sudah dikatakan pada penelitian ini, peneliti menggunakan teknik pengumpulan data dengan cara melakukan observasi, wawancara, dokumentasi dan studi kepustakaan. Untuk itu, Subjek dalam penelitian ini adalah Edward Halley selaku pemilik dari Adroady media dan Jessica selaku salah satu tim sales marketing Adroady media. Sedangkan Objek dalam penelitian ini adalah strategi komunikasi pemasaran yang digunakan Adroady Media. Sehingga penelitian ini, dapat dilakukan peneliti untuk mendalami mengenai strategi komunikasi pemasaran yang dilakukan Adroady media untuk memperkenalkan car videotron.

Analisis data yang digunakan peneliti yaitu dengan menggunakan teknik analisis data interaktif yang Menurut Miles dan Huberman dalam Sugiyono (2016:9299) pada buku yang berjudul Memahami Penelitian Kualitatif terdapat tiga langkah yaitu reduksi data, penyajian data dan penarikan kesimpulan.

Dan pada teknik keabsahan yang digunakan peneliti dalam penelitian ini adalah menggunakan teknik triangulasi. Penelitian ini menggunakan pendekatan kualitatif, dalam melakukan pemeriksaan keabsahan data penulis menggunakan triangulasi dengan sumber yang berarti membandingkan dan mengecek balik derajat kepercayaan informasi yang diperoleh melalui waktu dan alat yang berbeda dalam penelitian kuantitatif (Patton dalam Moleong, 2012:330). Jadi triangulasi merupakan alat bantu pendukung penulis dalam mengumpulkan data yang lengkap dengan melalui pengecekan data dan hasil observasi, wawancara dan narasumber.

\section{Hasil Penemuan dan Diskusi}

Adroady media merupakan salah satu perusahaan startup iklan di Indonesia yang saat ini sudah berjalan lebih dari dua tahun. Perusahaan ini terletak di Jl. Gudang Peluru Utara II Blok D, RT.1/RW.3, Kebon Baru, Tebet, Jakarta Selatan, Jakarta 12830. Perusahaan Adroady media ini menghadirkan cara beriklan digital mobile out of home yang sifatnya berbeda dengan media iklan lainnya. Media iklan yang ditawarkan yaitu menggunakan mobil sebagai media pendukungnya, berbasis digital, dan mengandalkan jaringan DOOH LED pertama di dunia. Media iklan ini disebut dengan car advertising atau car videotron. Pendiri dan pemilik dari Adroady media ini adalah Edward Halley, yang termotivasi membuat car videotron karena melihat bahwa media luar ruang mulai lesu dan ingin membangkitkan lagi media luar ruang yang berbeda dari sebelumnya.

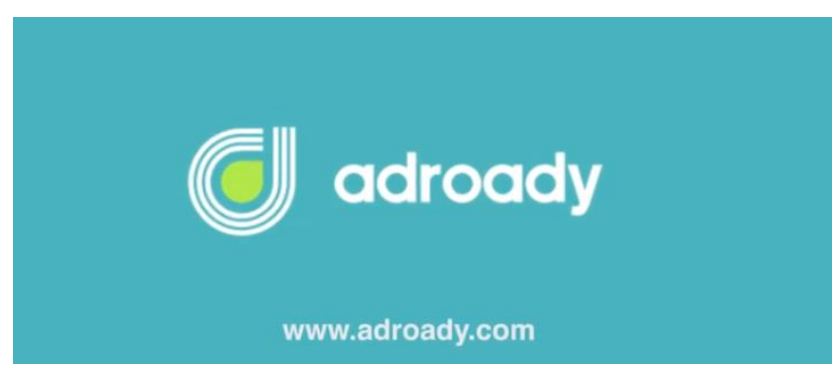

Gambar 1. Logo Adroady Media 
Berikut adalah hasil penemuan dan diskusi yang akan dijelaskan penulis dalam bentuk pembahasan yaitu:

a. Strategi Komunikasi Pemasaran

Dalam menyusun suatu strategi perencanaan komunikasi pemasaran, maka harus terdapat langkah yang efektif agar komunikasi pemasaran dapat terkomunikasikan dan dipromosikan dengan baik. Terdapat delapan langkah dalam perencanaan komunikasi pemasaran yang efektif menurut Agus Hermawan pada buku Komunikasi Pemasaran (2012):

1. Mengidentifikasi Khalayak Sasaran

Dalam sebuah pemasaran, mengidentifikasi audiens sasaran merupakan hal penting utama. Perusahaan yang baru perlu mengidentifikasi sasaran audiens yang dituju, apalagi car videotron merupakan media iklan baru pastinya Adroady media memiliki target audiensnya. Untuk adroady media sendiri, untuk sasaran target audiensnya merupakan semua kalangan masyarakat, baik itu corporate, kelas menengah kebawah, menengah ke atas dan perseorangan

2. Menentukan Tujuan Komunikasi

Setelah mengidentifikasi target audiens, selanjutnya adroady media menentukan tujuan komunikasi. Tujuan komunikasi ini bertujuan untuk membangun kesadaran masyarakat akan keberadaan car videotron, pengetahuan tentang media iklan baru berupa car videotron. Cara yang dilakukan adroady media yaitu dengan memberikan free-trial untuk para konsumen baru yang tertarik untuk mencoba menggunakan car videotron sebagai media iklan. Seperti yang diungkapkan oleh Edward Halley selaku Founder Adroady Media dalam memperkenal Car Videotron yaitu dengan datang ke para calon konsumen memberitahu keunggulan media iklan luar ruang baru ini, jika klien tertarik akan diberikan free-trial 1 minggu dan promo sampai $60 \%$. Lalu untuk ke masyarakat sendiri Adroady berfokus pada driver seperti taksi online atau pengendara yang ingin mendapat benefit tambahan jika dipasangkan jasa car videotron ini.

3. Merancang Pesan

Pada strategi merancang pesan ini yaitu bagaimana cara Adroady Media menyampaikan keunggulan dan karakteristik dari produk yang ditawarkan kepada konsumen agar mereka tertarik pada produk tersebut Pesan yang dirancang bisa berisi tentang keunggulan suatu produk, manfaat yang didapatkan jika beriklan menggunakan media Car Videotron. Di media sosial adroady media memberikan pesan-pesan iklan yang berisi tentang karakteristik Car Videotron itu sendiri dan video di youtube yang bersifat visual animasi yang sudah dipahami seperti Led Technology, Konten iklan dapat berubah sesuai lokasi dimana kendaraan itu berada, One Click, Camera Adroady, Real-time dashboard. Lalu tagline pada media sosial Adroady Media yaitu "The 1st Programmatic Mobile Digital Out Of Home" yang berarti merupakan media iklan luar ruang dengan program $\mathrm{DOOH}$. 
4. Memilih Saluran Komunikasi

Pada langkah ini, Adroady menggunakan saluran komunikasi secara personal atau komunikasi yang dilakukan secara langsung oleh dua orang atau lebih dalam menyampaikan pesan, sehingga masing-masing orang dapat mengetahui kebutuhan dan karakteristik orang lain serta membuat penilaian lebih cepat.

5. Menentukan Total Anggaran Pemasaran/ Promosi

Dalam melakukan sebuah pemasaran promosi, pasti membutuhkan biaya atau anggaran. Karena Adroady media merupakan perusahaan yang baru terjun di dunia periklanan, mereka masih belum banyak mengeluarkan biaya. bagaimanapun dalam melakukan sebuah promosi tentu membutuhkan biaya dan diperhitungkan berapa pengeluaran dan pendapatan Adroady media itu sendiri.

6. Menentukan Keputusan Atas Bauran Komunikasi Pemasaran Sebelum menentukan komunikasi pemasaran yang akan digunakan Adroady media perlu memperhatikan unsur perencanaan pemasaran yaitu dikenal dalam istilah 7P menurut Kotler dan Amstrong (2012), yaitu:

\section{a. Product}

Produk adalah mengelola unsur produk termasuk perencanaan dan pengembangan produk atau jasa yang tepat untuk dipasarkan dengan mengubah produk atau jasa yang ada dengan menambah dan mengambil tindakan yang lain yang mempengaruhi bermacam-macam produk atau jasa.

b. Price

Harga adalah suatu sistem manajemen perusahaan yang akan menentukan harga dasar yang tepat bagi produk atau jasa dan harus menentukan strategi yang menyangkut potongan harga, pembayaran ongkos angkut dan berbagi variabel yang bersangkutan.

c. Place

Distribusi yakni memilih dan mengelola saluran perdagangan yang dipakai untuk menyalurkan produk atau jasa dan juga untuk melayani pasar sasaran, serta mengembangkan sistem distribusi untuk pengiriman dan perniagaan produk secara fisik.

\section{d. Promotion}

Promosi adalah suatu unsur yang digunakan untuk memberitahukan dan membujuk pasar tentang produk atau jasa yang baru pada perusahaan melalui alat komunikasi pemasaran menurut Kotler dan Keller (2009) yaitu:

1. Iklan

Iklan menjangkau pembeli yang tersebar geografis, dapat membangun citra jangka panjang bagi produk dan memicu penjualan cepat. Bentuk promosi non-personal ini yang bertujuan menyampaikan pesan-pesan penjualan yang diarahkan kepada masyarakat melalui cara-cara yang persuasif yang bertujuan menjual barang, jasa atau ide. 


\section{Promosi Penjualan}

Perusahaan menggunakan alat promosi penjualan melalui kupon, premi atau semacamnya untuk menarik respons pembeli yang lebih kuat dan lebih cepat.

3. Hubungan Masyarakat dan Publisitas

Pemasar cenderung kurang memanfaatkan hubungan masyarakat, tetapi program yang dipikirkan dengan baik dan dikoordinasikan dengan elemen bauran komunikasi lainnya bisa sangat efektif, terutama jika perusahaan harus menantang konsepsi konsumen yang salah.

4. Acara dan Pengalaman

Ada banyak keuntungan bagi acara dan pengalaman yaitu (1) Relevan: acara atau pengalaman yang dipilih dengan baik dapat dianggap sangat relevan karena konsumen terlibat secara pribadi. (2) Melibatkan: berdasarkan kualitas tampilan langsung dan waktu rilisnya, acara dan pengalaman lebih melibatkan konsumen secara aktif. (3) Implisit: acara merupakan "penjualan lunak" tidak langsung.

5. Pemasaran Langsung dan Interaktif

Pemasaran langsung dan interaktif mempunyai banyak bentuk melalui telepon, online, dan secara pribadi yang pesannya dapat menarik individu, tersampaikan dengan cepat, dan pesan dapat diubah tergantung respons konsumen.

\section{Pemasaran Dari Mulut ke Mulut}

Pemasaran dari mulut ke mulut juga bisa berbentuk online dan offline yang mempunyai karakteristik yaitu kredibel, pribadi dan tepat waktu.

7. Penjualan personal

Merupakan alat promosi yang paling efektif pada siklus terakhir proses pembelian. Hal ini terjadi karena penjualan personal dapat membuat hubungan interaktif secara dekat untuk dapat mengenal konsumen secara lebih dalam dan lebih baik sehingga dapat memberikan respons yang tepat.

\section{e. Physical Evidence}

Bukti fisik merupakan suatu hal yang secara nyata turut memiliki kepuasan untuk membeli dan menggunakan produk jasa yang ditawarkan. Bukti fisik dari sebuah usaha jasa tentu nya sangat berpengaruh nanti nya dengan pemasaran yang dilakukan (Tjahjadi dan Sukendro, 2019).

\section{f. People}

Merupakan orang atau pegawai yang memberikan persepsi kepada konsumen lain tentang kualitas jasa yang pernah dibelinya dari perusahaan sehingga hal tersebut berpengaruh terhadap proses pembelian jasa yang bersangkutan (Tjahjadi dan Sukendro, 2019).

\section{g. Process}

Proses adalah semua prosedur aktual, mekanisme, dan aliran aktivitas yang digunakan untuk menyampaikan jasa. Elemen proses ini memiliki arti sesuatu untuk menyampaikan jasa. Proses dalam jasa merupakan faktor utama dalam bauran pemasaran jasa seperti pelanggan jasa akan senang merasakan sistem penyerahan jasa sebagai bagian jasa itu sendiri. 
7. Mengukur Hasil Promosi

Pengukuran hasil promosi dapat dilihat setelah promosi itu berjalan dan melihat hasil atau efek dari promosi yang telah dilakukan oleh Adroady media. Dan bisa kita lihat bahwa Adroady media juga sudah memiliki banyak pelanggan tetap seperti Blibli, Lazada, Marugame Udon, Sinarmas, Podomoro, Astra, dan masih banyak lainnya.

8. Mengelola dan Mengkoordinasikan Proses Komunikasi Pemasaran Terintegrasi

Setelah proses komunikasi pemasaran berjalan, selanjutnya Adroady media melihat dan mengikuti bagaimana perkembangan zaman saat ini sehingga produk dapat terintegrasi dengan baik. Selain itu Adroady juga sedang mempersiapkan peluncuran mobil baru dengan media pendukung motor, karena kita tahu bahwa masyarakat sudah bergantung pada ojek online.

\section{Simpulan}

Strategi komunikasi pemasaran yang digunakan Adroady Media dalam memperkenalkan car videotron sebagai media iklan luar ruang baru adalah dengan cara melalui langkah-langkah komunikasi pemasaran efektif yaitu mengidentifikasi khalayak yang dituju, merancang pesan, menentukan tujuan komunikasi, memilih saluran komunikasi, menentukan total anggaran pemasaran atau promosi, menentukan keputusan atas bauran komunikasi pemasaran, mengukur hasil promosi, mengelola dan mengkoordinasikan proses komunikasi pemasaran terintegrasi. Selain itu, kegiatan komunikasi pemasaran yang dilakukan dalam menarik konsumen yaitu personal selling, pemasaran langsung, dan acara atau pengalaman. dari ketiga kegiatan komunikasi pemasaran yang paling efektif menarik para calon konsumen adalah personal selling.

Personal selling merupakan media yang paling efektif digunakan dalam pemasaran Car Videotron. Dengan personal selling, perusahaan Adroady Media bisa menjalin hubungan yang baik dengan konsumen maupun calon konsumen dan membangun relasi yang baik.

\section{Ucapan Terima Kasih}

Ucapan terima kasih penulis sampaikan kepada seluruh narasumber yang telah bersedia meluangkan waktunya untuk melakukan wawancara dan memberikan banyak informasi kepada penulis selama proses pengumpulan data pada penelitian ini. Penulis juga berterima kasih kepada dosen pembimbing penulis, dan seluruh pihak yang telah membantu penulis dalam penelitian ini serta pihak Fakultas Ilmu Komunikasi Universitas Tarumanagara.

\section{Daftar Pustaka}

Claudio Tjahjadi \& Gregorius Genep Sukendro. (2019). Strategi Komunikasi Pemasaran Salon Dreadock Studio Indonesia. Prologia, 3, 66-73.

Hermawan, Agus. (2012). Komunikasi Pemasaran. Jakarta: Erlangga. 
Kriyantono, Rachmat. (2010). Teknik Praktis Riset Komunikasi. Jakarta:Kencana.

Kotler, Philip \& Gary, Armstrong. (2012). Prinsip-Prinsip Pemasaran (Jilid 1,Edisi 13). Jakarta: Erlangga.

Kotler, Philip \& Keller, Kevin Lane. (2009). Manajemen Pemasaran (Jilid 2,Edisi 13). Jakarta: Erlangga.

Moleong, Lexy J. (2012). Metodologi Penelitian Kualitatif. Bandung: PT Remaja Rosdakarya.

Sugiyono. (2016). Memahami Penelitian Kualitatif. Bandung: Alfabeta. 